\title{
EFFECTIVENESS OF SYNDROMIC STI CASE MANAGEMENT/RH TRAINING IN KNOWLEDGE AND PRACTICE OF AUXILIARY HEALTH WORKERS
}

\author{
Adhikari $\mathrm{C}^{1}$, Sherchan $\mathrm{L}^{2}$, Thapa $\mathrm{SB}^{1}$, Adhikari $\mathrm{LM}^{3}$
}

\begin{abstract}
INTRODUCTION: Auxiliary Health Workers (AHWs) are the undergraduate $2^{\text {nd }}$ class health workforce of Nepal. Syndromic Sexually Transmitted Infection Case Management/Reproductive Health (SSCM/RH) training for AHWs is designed to develop knowledge, attitude and skills. The purpose of this study was to examine the effectiveness of the training in knowledge and practice of AHWs.
\end{abstract}

MATERIAL AND METHODS: Achham district from where all AHWs were purposively selected for cross-sectional study. Total number of trained AHWs was 35 and untrained was 19, who were interviewed to fulfill the structured pretested questionnaire that included knowledge inventory and self reported practice. The data collected from $29^{\text {th }}$ May to $25^{\text {th }} \mathrm{July}$, 2005. Written consent was taken from respondents after permission taken from Achham DHO. Statistical tests used were mean, median, SD, Mann-Whitney U test, Spearman's rho and chi-square. Values with $\mathrm{p}<0.05$ was considered significant.

RESULTS : All AHWs were male, with mean age of 32.1 years. Regarding knowledge, the scores in all syndromes diagnosis and treatment regimen were significantly different in two groups except in two syndromes. Two practices were found significant. The median knowledge score was 20 (IQR, 16-22) and 16 (IQR, 12-20) in trained and untrained respectively. Similarly, median practice score was found 14 (IQR, 10-16) and 7 (IQR, 6-9) in trained and untrained respectively. In aggregate, both the practice score $(U=38.5, p<0.001$, two-tailed) and the knowledge score ( $U=205$, $\mathrm{p}=0.020$, two-tailed) of trained group significantly differed from that of untrained. Knowledge and practice score was also found positively and moderately correlated $(\mathrm{P}=0.616, \mathrm{p}<0.001$, two-tailed $)$.

CONCLUSION: The training was effectivein bringing about changes both in knowledge and practice of AHWs. The higher the knowledge level, the higher the practice level.

KEY WORDS: Sexual, Disease, Infection, Health worker, Knowledge, Practice

1. School of Health and Allied Sciences, Department of Public Health, Pokhara University, Kaski, Nepal

2. Central Department of Health, Physical and Population Education, Faculty of Education, Tribhuvan University, Kathmandu, Nepal

3. PhD scholar, Mewar University, Chittorgarh, Rajsthan, India

\author{
For Correspondence \\ Mr.Chiranjivi Adhikari \\ Assistant Professor, \\ School of Health and Allied Sciences, \\ Pokhara University, Lekhnath-12, Kaski, Nepal \\ Email: chiranadhikari@gmail.com
}




\section{INTRODUCTION}

More than 20 micro-organisms are responsible for transmission and cause of the sexually transmitted infections, which increase the risk of HIV and also other sequale. In many developing countries STDs have ranked among the top five diseases for seeking health care services. RH comprises the 30 percent of total morbidity and every fifth case is STD patient in developing countries. In 15 - 44 age-group, STDs (excluding HIV) are second only to maternal factors as causes of disease, death and healthy life lost. The presence of an untreated STD can also increase the risk of both acquisition and transmission of HIV by factor output ten. ${ }^{1-3}$

Lab-based and clinical diagnosis is not feasible in the resource-constrained areas especially hill and mountain of the developing countries like Nepal. Syndromic case management is based on classifying the main causative agents giving rise to a particular clinical condition and special protocols on such clinical condition works against the microorganisms collectively. SSCM is better than the clinical or laboratory based approach in that patients receive immediate treatment, thereby interrupting the chain of infection early, and without the expense of laboratory costs. STD treatment should offer a cure rate of at least 95 percent. Knowledge of accurate drug regimens is a crucial in this regard. $^{1-3}$ The institutional prevalence of STI/RTI/HIV in Nepal out of total OPD cases shows $0.22 \%$ to $0.34 \%$ in 1996 1999 period showing quite lower status. ${ }^{3,4}$

A study conducted in Achham district resulted in 40 percent of the respondents migrated internationally and of these 38 percent migrated to Mumbai only, the rest migrated to other states in India. Among the international migrants from Achham going to Mumbai 7.7 percent were found HIV positive and other neighboring districts have similar seroprevalences. $^{5}$

Knowledge, attitude and practice regarding STI/HIV has not been found sufficient among doctors and paramedics. ${ }^{3}$ Trainings regarding STICM is paramount for HCPs in controlling the transmission of STDs, hence controlling and preventing the general population from sequalae of STDs and further prevent HIV spread. Clinical setting is also cornerstone of health education and condom distribution that promote the primary prevention of STIs including AIDS. ${ }^{1}$

\section{MATERIAL AND METHODS}

Cross-sectional comparative design was applied and cross sectional data were utilised to compare the knowledge and practice scores of trained and untrained AHWs regarding
$\mathrm{SSCM} / \mathrm{RH}$ training. The participants were assigned as trained and untrained from the record of training section of DHO Achham, which was purposively selected. The pretested interview schedule included 30 structured questions containing knowledge inventory and self-reported practice. These questions incorporated the knowledge and practice of seven syndromes viz., Urethral Discharge Syndrome (UDS), Vaginal Discharge Syndrome (VDS), Inguinal Swelling Syndrome (ISS), Lower Abdominal Pain Syndrome (LAPS), Scrotal Swelling Syndrome (SSS), Neonatal Conjunctivitis Syndrome (NCS) and Genital Ulcer Syndrome (GUS). The administration of the interview was in group as well as individual. Data collection was done from $29^{\text {th }}$ May to $25^{\text {th }}$ July, 2005. The ethical permission was taken from DHO Achham and consent was verbally taken from each participants. The statistical analyses applied were Wilcoxon Mann-Whitney U test, Spearman's rho( $\rho)$, chi-square test. Statistical software used were SPSS version 17.1, endnote version 3 and MS-excel 2007.

\section{RESULTS}

The total number of posts of AHWs in DHO Achham was 77, where only 54 were present during the interview and all were male. More than one-third $\left(\mathrm{n}_{1=} 19,35 \%\right)$ were untrained and almost two-third $\left(n_{2}=35,65 \%\right)$ were found to be trained in $\mathrm{SSCM} / \mathrm{RH}$ training.

Table 1: Demographic characteristics of AHWs

\begin{tabular}{|l|l|l|l|l|}
\hline \multirow{2}{*}{ Characteristics } & \multicolumn{2}{c|}{ Trained (n=35) } & \multicolumn{2}{c|}{ Untrained (n=19) } \\
\cline { 2 - 6 } & Frequency & $\%$ & Frequency & $\%$ \\
\hline Age in completed years & 1 & 2 & 4 & 21 \\
$20-24$ & 10 & 29 & 7 & 37 \\
$25-29$ & 14 & 40 & 5 & 26 \\
$30-34$ & 10 & 29 & 3 & 16 \\
$35+$ & $32.8 \pm 7.1$ & & $29.6 \pm 6.9$ & \\
Mean \pm SD & & & & \\
\hline Duration of experience in completed years & 0 & 0 & 8 & 42 \\
$<5$ & 17 & 49 & 6 & 32 \\
$5-9$ & 13 & 37 & 4 & 21 \\
$10-14$ & 5 & 14 & 1 & 5 \\
$15+$ & $10.1 \pm 3.8$ & & $6.3 \pm 5.3$ & \\
Mean \pm SD & 15 & 43 & 7 & 37 \\
\hline Educational level completed & 15 & 43 & 9 & 47 \\
CMA & 5 & 14 & 3 & 16 \\
Certificate/plus two with CMA & $12.6 \pm 1.7$ & & $12.7 \pm 1.7$ & \\
Bachelor with CMA & & & \\
Mean \pm SD years of schooling & & & & \\
\hline
\end{tabular}




\section{Demographic Characteristics of AHWs}

The higher duration of experience was found among the trained and so in the case of age (table 1). The mean years of experience was 10.3 for trained and 6.9 for untrained. The range of experience of AHWs was 2 to 21 years. The mean age of the trained AHWs was 32.2 and untrained was 29.3 years. The range of age of AHWs was from 20 to 49 years. The higher educational level was found among the untrained. Mean years of schooling of trained was 12.6 years and that of untrained was found to be 12.7 .

\section{Practices of AHWs in STI/HIV cases}

The practice score was found to be significantly higher among the trained than that of untrained in number of patients treated within three months $(p=0.002)$ and perception towards STI/HIV clients $(p=0.026)$. However, practice was in significant in condom distribution and tracing of HIV cases. (table 2)

Table 2: Practices of AHWs in syndromic management of STIs

\begin{tabular}{|l|l|l|l|}
\hline Types of practices & $\begin{array}{l}\text { Trained } \\
(\mathbf{n}=\mathbf{3 5})\end{array}$ & $\begin{array}{l}\text { Untrained } \\
(\mathbf{n}=\mathbf{1 9})\end{array}$ & p-value \\
\hline $\begin{array}{l}\text { No. of STI patients treated in last 3 months } \\
<20\end{array}$ & 6 & 15 & $0.002^{* *}$ \\
$=20$ & 29 & 4 & \\
\hline $\begin{array}{l}\text { No. of condom distributed in last 3 months } \\
<1000\end{array}$ & 25 & 16 & 0.47 \\
$=1000$ & 10 & 3 & \\
\hline $\begin{array}{l}\text { Traced no. of suspected HIV cases in last 3 months } \\
<10\end{array}$ & 32 & 17 & 0.79 \\
$=10$ & 3 & 2 & \\
\hline $\begin{array}{l}\text { Perception towards STI/HIV clients } \\
\text { Positive }\end{array}$ & 27 & 9 & $0.026^{*}$ \\
Negative & 8 & 10 & \\
\hline
\end{tabular}

*Significant at 0.05 level ** Significant at 0.01 level

Knowledge of AHWs in diagnosing the syndromes \& treatment regimens

Knowledge score on diagnosing each syndrome correctly was significantly better among the trained than untrained except in GUS and ISS (table 3). Knowledge on treatment regimens of all was found to be better among the trained than untrained. $(\mathrm{p}<0.05)$ (table 3$)$.

Table 3: Knowledge of AHWs in diagnosis of syndromes and treatment regimens

\begin{tabular}{|c|c|c|c|c|c|c|}
\hline \multirow[t]{2}{*}{ Types of syndromes } & \multicolumn{3}{|c|}{ Knowledge on diagnosis } & \multicolumn{3}{|c|}{ Knowledge on treatment regimen } \\
\hline & $\begin{array}{l}\text { Trained } \\
(\mathrm{n}=35)\end{array}$ & $\begin{array}{l}\text { Untraine } \\
d(n=19)\end{array}$ & p-value & $\begin{array}{l}\text { Trained } \\
(n=35)\end{array}$ & $\begin{array}{l}\text { Untrained } \\
(\mathrm{n}=19)\end{array}$ & p-value \\
\hline $\begin{array}{l}\text { Definition of syndromic diagnosis } \\
\text { Correct } \\
\text { Incorrect }\end{array}$ & $\begin{array}{r}29 \\
6\end{array}$ & & $<0.001^{* *}$ & & & \\
\hline $\begin{array}{l}\text { Knowledge on fourC's } \\
\text { Correct } \\
\text { Incorrect }\end{array}$ & $\begin{array}{l}22 \\
13\end{array}$ & $\begin{array}{c}6 \\
13\end{array}$ & $0.042^{*}$ & & & \\
\hline $\begin{array}{l}\text { Diagnosis of UDS } \\
\text { Correct } \\
\text { Incorrect }\end{array}$ & $\begin{array}{r}27 \\
8\end{array}$ & $\begin{array}{r}7 \\
12\end{array}$ & $0.003 * *$ & $\begin{array}{l}22 \\
13\end{array}$ & $\begin{array}{r}6 \\
13\end{array}$ & $0.028^{*}$ \\
\hline $\begin{array}{l}\text { Diagnosis of VDS } \\
\text { Correct } \\
\text { Incorrect }\end{array}$ & $\begin{array}{l}21 \\
14\end{array}$ & $\begin{array}{c}4 \\
15\end{array}$ & $0.006^{* *}$ & $\begin{array}{r}28 \\
7\end{array}$ & $\begin{array}{c}7 \\
12\end{array}$ & $0.002^{* *}$ \\
\hline $\begin{array}{l}\text { Diagnosis of GUS } \\
\text { Correct } \\
\text { Incorrect }\end{array}$ & $\begin{array}{r}9 \\
26\end{array}$ & $\begin{array}{c}5 \\
14\end{array}$ & 0.962 & $\begin{array}{l}22 \\
13\end{array}$ & $\begin{array}{r}6 \\
13\end{array}$ & $0.028^{*}$ \\
\hline $\begin{array}{l}\text { Diagnosis of SSS } \\
\text { Correct } \\
\text { Incorrect }\end{array}$ & $\begin{array}{l}19 \\
16\end{array}$ & $\begin{array}{r}4 \\
15\end{array}$ & $0.018^{*}$ & $\begin{array}{r}30 \\
5\end{array}$ & $\begin{array}{r}11 \\
8\end{array}$ & $0.022^{*}$ \\
\hline $\begin{array}{l}\text { Diagnosis of ISS } \\
\text { Correct } \\
\text { Incorrect }\end{array}$ & $\begin{array}{l}18 \\
17\end{array}$ & $\begin{array}{r}9 \\
10\end{array}$ & 0.776 & $\begin{array}{l}20 \\
15\end{array}$ & $\begin{array}{r}5 \\
14\end{array}$ & $0.030^{*}$ \\
\hline $\begin{array}{l}\text { Diagnosis of LAPS } \\
\text { Correct } \\
\text { Incorrect }\end{array}$ & $\begin{array}{l}24 \\
11\end{array}$ & $\begin{array}{r}6 \\
13\end{array}$ & $0.009^{* *}$ & $\begin{array}{r}31 \\
4\end{array}$ & $\begin{array}{r}12 \\
7\end{array}$ & $0.027^{*}$ \\
\hline $\begin{array}{l}\text { Diagnosis of NCS } \\
\text { Correct } \\
\text { Incorrect }\end{array}$ & $\begin{array}{l}25 \\
10\end{array}$ & $\begin{array}{c}5 \\
14\end{array}$ & $0.001 * *$ & $\begin{array}{l}22 \\
13\end{array}$ & $\begin{array}{r}6 \\
13\end{array}$ & $0.028^{*}$ \\
\hline
\end{tabular}

*Significant at 0.05 level ** Significant at 0.01 level

\section{Inferential Statistics of trained and untrained AHWs}

The median knowledge and practice score among the trained (20 (IQR, 16-22) and 14 (IQR 10-16)) respectively was higher than that of untrained (16 (IQR, 12-20) and 7 (IQR 6-9)) (table $5)$. However, the aggregate result both in practice $(\mathrm{U}=38.5$, $\mathrm{p}<0.001$, two-tailed) and knowledge score ( $\mathrm{U}=205, \mathrm{p}=0.020$, two-tailed) was significant when applying Wilcoxon MannWhitney U test. (table 4) The correlation between knowledge and practice score showed positively moderate $(\rho=0.616$, $\mathrm{p}<0.001$, two-tailed). (table 4) 
Table 4: Mann-Whitney $U$ and Correlation Tests among trained and untrained $\mathrm{AHWs}$

\begin{tabular}{|l|l|l|l|l|l|l|}
\hline Scores & $\begin{array}{l}\text { Median } \\
(\mathrm{IQR})\end{array}$ & $\begin{array}{l}\text { Mann- } \\
\text { Whitney } \\
\text { U score }\end{array}$ & z-score & p-value & $\begin{array}{l}\text { Spearman's } \\
\text { rho }(\boldsymbol{\rho})(\mathbf{n}=\mathbf{5 4})\end{array}$ & -value \\
\hline $\begin{array}{c}\text { Knowledge score } \\
\text { Trained (n=35) } \\
\text { Untrained (n=19) }\end{array}$ & $\begin{array}{c}20(16-22) \\
16(12-20)\end{array}$ & $205.0^{*}$ & -2.324 & 0.020 & \multirow{2}{*}{$0.616^{* *}$} & $<0.001$ \\
\cline { 1 - 5 } $\begin{array}{c}\text { Practice Score } \\
\text { Trained(n=35) } \\
\text { Untrained (n=19) }\end{array}$ & $\begin{array}{c}14(10-16) \\
7(6-9)\end{array}$ & $38.5^{* *}$ & -5.344 & $<0.001$ & & \\
\hline
\end{tabular}

*Significant at 0.05 level (two-tailed test) ** Significant at 0.01 level (two-tailed test)

\section{DISCUSSION}

AHWs are the lower medium level health workforce mostly working at primary health care level where sophisticated lab and other instruments are not easily available giving rise to the importance of syndromic approach in STI case management. There is a provision to provide such training to every AHWs along with SSCM guidelines protocol or handbook. However, the protocol is provisioned for untrained also. Pre-service training lacks in proper knowledge and skills regarding STI case management. ${ }^{6}$ Some of the AHWs also run their private clinics in off-hours and STI cases are met at these clinics because of the higher confidentiality. A study conducted among private practitioners in Jamaica ${ }^{7}$ revealed that short (half-day) seminars in 3-4 months interval is effective in different STI case management categories. SSCM has been designed from three to seven day training from syndromic approach that follows the simple protocol. Although reproductive health $(\mathrm{RH})$ training is conducted for seven to nine days, which includes various components of reproductive health rather than SSCM alone. Statistical significance was observed in almost contents of knowledge including diagnosis and treatment regimens and practice. However, knowledge regarding diagnosis of ISS and GUS was not found significant. Service experience was quite higher among the trained (mean=10.3 years) than the untrained (mean $=6.9$ years) and there was not a single respondent who mentioned about the participation in refresher training. The mean age was higher among the trained (32.1 years) than the untrained (29.3 years). Participants indicated that inadequate time $(52.9 \%)$, facilities/equipments $(51.5 \%)$, and poorly sanctioned staffing $(47.1 \%)$ interfered with implementation of recommended practices. ${ }^{8-9}$ Despite these barriers, inferential analysis showed that the training was effective to bring about the changes both in knowledge and practice of syndromic approach as to manage STIs in rural and remote settings.

\section{CONCLUSION}

The SSCM/RH training was found to be effective to bring about changes in knowledge and practice of AHWs in STI case management. The knowledge regarding the diagnosis and treatment increases the practice level of STICM.

\section{ACKNOWLEDGEMENTS}

We sincerely thank Mr. Shailendra Shrestha, DPH officer and all the AHWs and staffs working under DHO, Achham district. We also appreciate the supports from staffs of DDC of Achham and Mr. Dambar Ghimire of GTZ-HSSP Achham and Mr. Anirudra Sharma of UNICEF Achham. Last but not the least we can't help thanking Mr. Tek Bdr. Chhetri who helped in editing the language.

Conflict of interest: None declared

\section{REFERENCES}

1. WHO, Global prevalence and incidence of selected curable sexually transmitted infections, overview and estimates, Switzerland: Geneva, 2001. [cited 2012 Nov 15]. Available from: www.who.int

2. WHO, management of patients with sexually transmitted diseases,WHO study group, Switzerland: Geneva,1991.[cited 2012 Nov 15]. Available from: www.who.int

3. NCASC. National STI case management guidelines. Kathmandu, Nepal: Ministry of Health and Population, 2001.

4. AIDS Watch, March2003 [online magazine].[cited 2012 Nov14]. Available from: www.jwatch.org.

5. UNAIDS, NCASC, The HIVAIDS/STD Situation and the National Response in Nepal Country Profile, Nepal, April, 2004.

6. Malhotra S, Khurshid A, Hendricks KA, Mann JR. Medical school sexual health curriculum and training in the United States. J Natl Med Assoc. 2008 Sep;100(9):1097-106. PMid: 18807442

7. Green M, Hoffman IF, Brathwaite A, Wedderburn M, Figueroa P, Behets $F$, et al. Improving sexually transmitted disease management in the private sector: the Jamaica experience. AIDS. 1998;12 Suppl 2:S67-72.PMid:9792363

8. Dreisbach S, Devine S, Fitch J, Anderson T, Lee T, Rietmeijer C, Corbett KK. Can experimental-didactic training improve clinical STD practices? Sex Transm Dis. 2011 Jun;38(6):51621PMid:21233790

9. RL Cane. Understanding Health Care Outcomes Research, Jones and Barlett, Boston, 2004.p.221. 